Published in final edited form as:

Org Lett. 2009 March 19; 11(6): 1353-1356. doi:10.1021/ol900143j.

\title{
Erythromycins $\mathrm{H}$ and I From Actinopolyspora sp. YIM90600, a New Halophilic Actinomycete
}

\author{
Sheng-Xiong Huang ${ }^{\dagger}$, Li-Xing Zhao ${ }^{\dagger} \S$, Shu-Kun Tang ${ }^{\S}$, Cheng-Lin Jiang ${ }^{\S}$, and Ben \\ Shen ${ }^{\dagger, \#, \ddagger}$ \\ †Division of Pharmaceutical Sciences, University of Wisconsin, Madison, Wisconsin 53705-2222 \\ \#University of Wisconsin National Cooperative Drug Discovery Group, Madison, Wisconsin \\ 53705-2222
}

‡Department of Chemistry, University of Wisconsin, Madison, Wisconsin 53705-2222

§Yunnan Institute of Microbiology, Yunnan University, Kunming 650091, PR China

\begin{abstract}

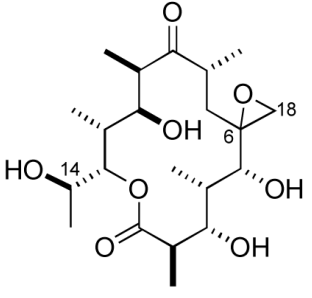

Erythromycin $\mathrm{H}, 1$

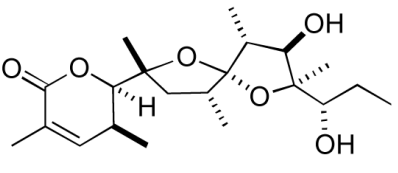

Erythromycin I, 2

Erythromycins $\mathrm{H}$ and I, shunt metabolites of the clinically important antibacterial drug erythromycin A, have been isolated from the new actinomycete Actinopolyspora sp. YIM90600. A. sp. YIM90600 joins Saccharopolyspora erythraea and Aeromicrobium erythreum as only the third actinomycete reported capable of producing erythromycins. In addition to producing new erythromycins, $A$. sp. YIM90600, even under suboptimal conditions, is a high titer producer of erythromycin $\mathrm{C}$. The presence of the $\mathrm{C}-14$ hydroxyl moiety and the 6,18-epoxide in the 14membered lactone nucleus of erythromycin $\mathrm{H}$ and the spiro-fused dipyran moiety of erythomycin I sheds new insight into the size and structural diversity of erythromycin analog libraries accessible by combinatorial biosynthesis.
\end{abstract}

Erythromycin A and related analogues are produced by actinomycetes and have been clinically used for more than 50 years. The erythromycins are considered first line therapeutics for the treatment of upper and lower respiratory tract infections. Their antibacterial activity is attributed to inhibition of protein synthesis resulting from binding to the peptidyltransferase site of the bacterial $50 S$ ribosomal subunit.1 A significant problem

bshen@pharmacy.wisc.edu.

Supporting Information Available Detailed experimental procedures, NMR spectra (1D and 2D) for compounds 1 and 2. This material is available free of charge via the Internet at http://pubs.acs.org. 
with the first-generation macrolide erythromycin $\mathrm{A}$ is its facile decomposition under acidic conditions resulting in loss of activity and undesirable gastrointestinal side effects.2 Efforts to diversify the erythromycin scaffold in order to minimize side effects and in vivo degradation have constituted a major area of research resulting in second generation macrolides such as clarithromycin, 3 azithromycin, 4 and roxithromycin5. The development of resistance to second generation macrolides, most notably in the form of ribosomal mutation ( $\mathrm{erm}$ ) or by efflux (mef) mechanisms, has hastened a third generation of macrolide antibiotics including cethromycin (ABT-773),6 EP-420,7 and BAL-194038; these agents constitute recent additions to the repertoire of clinical antibacterial therapeutics. In addition to their use as antibacterial therapeutics, erythromycin derivatives have recently been reported to inhibit HIV-1 replication in macrophages through modulation of MAP kinase activity.9

Actinopolyspora YIM90600, obtained from a dried salt lake in Xingjiang province, China, requires 8-30\% salt for growth and shows little 16S rRNA gene sequence identity relative to its nearest halophilic neighbor species, Actinopolyspora halophila, Actinopolyspora mortivallis and Actinopolyspora iraqiensi.10 Thus, A. sp. YIM90600 likely represents a new Actinopolyspora species. Moreover, A. sp. YIM90600, the culture extracts of which displayed significant antibiotic activity and moderate cytotoxicity, may represent the first strain belonging to the genus Actinopolyspora to be examined for its ability to produce bioactive natural products. Here we report the structures of erythromycins $\mathrm{H}(\mathbf{1})$ and I (2). Isolation of these new natural products from $A$. sp. YIM90600 inspires new ideas for diversity-oriented combinational biosynthesis of erythromycin libraries.

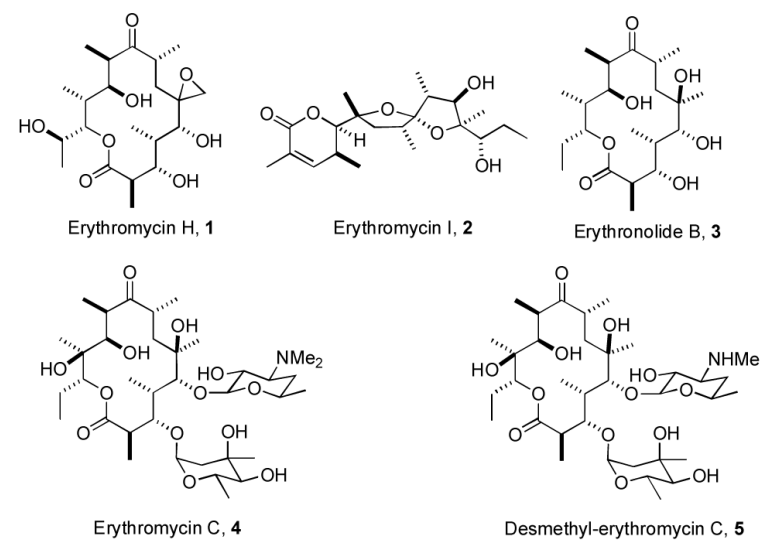

Strain YIM90600 was cultivated in a NaCl-based medium $(10 \times 0.5 \mathrm{~L})$ for 28 days with vigorous shaking. Solid phase extraction of the broth using HP-20 resin, filtration through cheesecloth, and compound elution from the resin with acetone afforded, after solvent removal under vacuum, a gummy extract that was subjected to fractionation on silica gel. Multiple rounds of silica gel chromatography and C18 reverse phase HPLC afforded 1, 2, erythronolide B (3), erythromycin C (4) and demethyl-erythromycin C (5). Structure elucidation of $\mathbf{1}$ was straightforward due to its structural similarity to known compounds 3-5. High resolution ESI-MS (HRESIMS) analysis of 1 gave an $[\mathrm{M}+\mathrm{Na}]^{+}$ion at $\mathrm{m} / 2$ 439.2292 consistent with a molecular formula of $\mathrm{C}_{21} \mathrm{H}_{36} \mathrm{O}_{8}$ (calcd for $\mathrm{C}_{21} \mathrm{H}_{36} \mathrm{O}_{8} \mathrm{Na}$, 
439.2302). Acquisition and analysis of NMR data for 1 (Table 1) and comparison to data acquired for 3-5 suggested compound $\mathbf{1}$ to be a 14-membered macrolactone possessing an erythromycin-like core scaffold. This assignment was confirmed by high resolution 2D NMR spectroscopy. The regiochemistry of hydroxylation was independently assigned on the basis of HMQC and HMBC data (Figure 1). A spirocyclic epoxide at the C-6 was evident for 1 based on the observation of signals in the NMR spectrum $\left[\delta_{\mathrm{C}} 58.8(\mathrm{~s})\right.$ and $\delta_{\mathrm{C}} 46.9(\mathrm{t})$, $\delta_{\mathrm{H}} 2.76$ and 2.27 (each $1 \mathrm{H}, \mathrm{d}, J=7.0 \mathrm{~Hz}$ )], as well as, $\mathrm{HMBC}$ correlations of $\mathrm{H}_{2}-19$ with C-5, C-6, and C-7. With the exception of C-14, the stereochemistry of 1 was deduced by considering its biosynthetic origin and comparative analysis of NMR data relative to 3-5. The relative configuration of $\mathbf{1}$ at $\mathrm{C}-14$ could not be determined from spectroscopic data alone. However, the almost indentical coupling constants between $\mathrm{H}-13$ and $\mathrm{H}-14$, as well as, similarities of other NMR data with those of (14R)-14-hydroxy TB-010 and (14R)-14hydroxy TE-031 allowed us to tentatively assign an $R$ configuration to C-14 of $\mathbf{1 . 1 1}$

The molecular formula of $\mathrm{C}_{21} \mathrm{H}_{34} \mathrm{O}_{6}$, determined by HRESIMS $\left([\mathrm{M}+\mathrm{Na}]^{+} 405.2244\right)$ and NMR data, indicated that $\mathbf{2}$ is also a C-21 polyketide having five points of unsaturation. Data derived from ${ }^{1} \mathrm{H},{ }^{13} \mathrm{C}$, and HSQC NMR spectra (Table 1) were consistent with the presence of one carboxyl group $\left(\delta_{\mathrm{C}} 166.7\right)$, one trisubstituted double bond $\left(\delta_{\mathrm{C}} 146.4\right.$, d; $\left.\delta_{\mathrm{C}} 126.8, \mathrm{~s}\right)$, three oxygenated tertiary carbons $\left(\delta_{\mathrm{C}} 82.1,82.3,113.8\right)$, six methines, three of which are oxygenated $\left(\delta_{\mathrm{C}} 84.8,86.4,77.3\right)$, two methylene moieties ( $\left.\delta_{\mathrm{C}} 40.0,23.6\right)$, and seven methyl groups. Two resonances in the ${ }^{1} \mathrm{H}$ NMR spectrum $(\delta 3.05, \mathrm{~d}, J=5.5 \mathrm{~Hz}, \mathrm{OH}-11 ; 2.98$, br, $\mathrm{OH}-13)$ lacking any carbon HSQC correlations were assigned as exchangeable protons accounting for all 34 protons consistent with the molecular formula. The presence of two hydroxyl moieties supported by this data is consistent with three heterocyclic moieties accounting for the degree of unsaturation displayed by 2 .

Consistent with the UV-vis data, $\mathbf{2}$ possesses a six-membered $\alpha, \beta$-unsaturated lactone, as assigned on the basis of ${ }^{1} \mathrm{H}_{-}{ }^{1} \mathrm{H}$ COSY correlations involving $\mathrm{H}-3 / \mathrm{H}-4$ and $\mathrm{H}-4 / \mathrm{H}-5, \mathrm{H}_{3}-17$, and long-range ${ }^{1} \mathrm{H}_{-}{ }^{13} \mathrm{C}$ HMBC correlations from the vinylic methyl group $\left(\mathrm{H}_{3}-16, \delta_{\mathrm{H}} 1.90\right)$ to $\mathrm{C}-1\left(\delta_{\mathrm{C}} 166.7\right), \mathrm{C}-2$, and $\mathrm{C}-3\left(\delta_{\mathrm{C}} 146.4\right)$ and from the secondary methyl group $\left(\mathrm{H}_{3}-17, \delta_{\mathrm{H}}\right.$ $1.07)$ to $\mathrm{C}-3, \mathrm{C}-4\left(\delta_{\mathrm{C}} 31.1\right)$, and $\mathrm{C}-5(\delta 84.8)$. Further analysis of the ${ }^{1} \mathrm{H}-{ }^{1} \mathrm{H}$ COSY data revealed carbon connectivities of C-7/C-8/C-19, C-20/C-10/C-11, and C-13/C-14/C-15 (Figure 1). Strong HMBC correlations of methyl signals of $\mathrm{H}_{3}-18, \mathrm{H}_{3}-19, \mathrm{H}_{3}-20$, and $\mathrm{H}_{3}-21$ with corresponding carbons (Figure 1) support the assigned fragment connectivity deduced from COSY spectrum via three oxygenated tertiary carbons C-6, C-9, and C-12, respectively. Analysis of COSY correlations of $\mathrm{OH}-11$ with $\mathrm{H}-11$ and of $\mathrm{OH}-13$ with $\mathrm{H}-13$ as well as HMBC cross peaks of OH-11 with C-11 and C-12, and of OH-13 with C-14 confirmed the location of the two hydroxyl groups. These findings are consistent with the C-9 spiroketal $\left(\delta_{\mathrm{C}} 113.8, \mathrm{~s}\right)$, which along with the lactone moiety, satisfy the degree of unsaturation originally determined on the basis of initial MS and 1D NMR data.

The ROESY spectrum was used to establish the relative stereochemistry of $\mathbf{2}$. Although we have not yet determined its absolute stereochemistry, we envision $\mathbf{2}$ to possess the same stereochemistry as erythromycin A. The stereochemical configuration at C-9 was consistent with ROESY correlations of $\mathrm{H}_{3}-19$ with $\mathrm{H}-10$, and of $\mathrm{H}_{3}-20$ with $\mathrm{H}-8$ as shown in Figure 2. ROESY cross-peaks of $\mathrm{H}_{3}-18$ with $\mathrm{H}-8$ and of $\mathrm{H}_{3}-21$ with $\mathrm{H}-10$ confirmed the $R$ 
configuration of C-6 and C-12 in $\mathbf{2}$. The configurations of all other asymmetric centers in $\mathbf{2}$ appear to be identical to those of the corresponding centers in $\mathbf{4}$ and $\mathbf{5}$.

Both $\mathbf{1}$ and $\mathbf{2}$ are shunt metabolites of $\mathbf{4}$. The biogenetic proposal in Scheme 1 suggests that the six rounds of condensation and reduction en route to both $\mathbf{1}$ and $\mathbf{2}$ are similar to those described for erythromycin A biosynthesis. 12 However, in contrast to the erythromycin A paradigm, release of the polyketide is envisioned to proceed in two ways (Scheme 1); macrolactonization (path a) affords 6 whereas nucleophilic attack by the C-5 hydroxyl upon the $\mathrm{C}-1$ thioester affords lactone $\mathbf{2 a}$ (path b). Macrolactone $\mathbf{6}$ is a substrate for multiple oxygenases, likely cytochrome P-450s. C-6 oxidation affords $\mathbf{3}$, one of the compounds isolated from A. sp. YIM90600 and a possible precursor to epoxide 7. Additionally, oxidation of $\mathbf{6}$ at C-14 is envisioned to afford 8 . Although the relationship of $\mathbf{3}, \mathbf{7}$, and $\mathbf{8}$ to each other is not certain, it is clear that one or more of these compounds is a precursor to 1 as $\mathbf{1}$ bears both the epoxide of $\mathbf{7}$ and the $\mathrm{C}-14$ hydroxyl moiety of $\mathbf{8}$. The $\beta$-hydroxy lactone 2a produced in path $\mathrm{b}$ likely undergoes spontaneous dehydration although it is not clear at present if this occurs before or after the action of C- 6 and C- 12 oxygenases to produce tetraol $\mathbf{2 c}$. It is particularly intriguing that $\mathrm{C}-6$ oxidation both in paths a and b is likely catalyzed by the same oxygenase and that the $\mathrm{C}-12$ oxygenase normally operative during erythromycin A and C (4) biosynthesis acts upon $\mathbf{2 a}$ (or its C-6 oxidized product) but does not oxidize C-12 during biosynthesis of $\mathbf{1} .12,13$ Following installation of the C-6 and C-12 hydroxyl moieties $\mathbf{2 c}$ likely undergoes spontaneous spiroketalization to render $\mathbf{2}$ analogous to the known acid-catalyzed inactivation of erythromycin A.14

The discovery of $\mathbf{1}$ and $\mathbf{2}$ provides new insights into erythromycin biosynthesis. First, is that that TE domain within the erythromycin cluster from A. sp. YIM 90600 is responsible for cyclizations resulting in 14- or 6-membered lactones. This supports earlier studies into TE substrate flexibility and diversity of product formation associated with this TE; these features have been confirmed by artificially constructed mutants.15 Second, the two P450 monooxygenases in the erythromycin gene cluster, the C-6 oxygenase EryF and C-12 oxygenase EryK, are generally considered to act preferentially on macrolide substrates. 13 However, the isolation of $\mathbf{2}$ suggests that these oxygenases act equally well on either linear substrate $\mathbf{2 a}$ or $\mathbf{2 b}$ (Scheme 1). Contrasting this apparent substrate promiscuity for EryK is that 1 lacks C-12 oxygenation indicating that EryK function is either abolished or redirected during biosynthesis of $\mathbf{1}$. Third, C-14 oxidation in $\mathbf{1}$ is likely carried out by an oxygenase whose gene resides beyond the erythromycin biosynthetic gene cluster as there are no known $\mathrm{C}-14$ oxygenases within the erythromycin cluster. C-14 oxygenated erythromycins have been noted although none are produced alongside erythromycin A.11 Thus, $A$. sp YIM90600 may exploit a unique C-14 oxygenase gene beyond its erythromycin cluster. Alternately, the EryK homolog present in this new halophilic actinomycete may simply process macrolide $\mathbf{6}$ (or some derivative of it) in a way that leads to hydroxylation at C-12 instead of C-14. Such a scenario is reminiscent of P450 PicK (CYP107L1) which is known to be involved in the production of four antibiotics by Streptomyces venzuelae by hydroxylating the $\mathrm{C}-10$ and/or C-12 positions of 12- and 14-membered macrolides including picromycin. 16 
Perhaps the most interesting insight into erythromycin biosynthesis by A. sp. YIM90600 is gleaned by considering the C- 6 epoxide of $\mathbf{1}$ which is without precedent among publicly disclosed erythromycin analogues. The presence of this epoxide raises the possibility that it may result from the same P-450 responsible for C-6 hydroxylation in 3-5, presumably an EryF homolog although EryF is not yet known to be bifunctional in this manner. Examples of such dual activity P-450s are known, as in the case for biosynthesis of scopolamine17 which is catalyzed the bifunctional hyoscyamine 6- $\beta$-hydroxylase, but are exceedingly rare. More often, such bifunctional P-450s differ in their regiochemical selectivity of hydroxylation and/or epoxidation as in MycG-catalyzed production of mycinamicins I (an epoxidation product), II (a dual hydroxylation/epoxidation product), and $\mathrm{V}$ (hydroxylation product).16 The epoxide of $\mathbf{1}$ may, alternatively, indicate the role of an OleP-like enzyme. OleP is well known to epoxidize the C-8 position of a related 14-membered macrolide during oleandomycin biosynthesis. 18 The high degree of structural similarity between $\mathbf{6}$ and the OleP substrate suggests that 1 may well result from the action of an OleP homolog with C-6 instead of C-8, selectivity of epoxidation. Significant from the perspective of combinatorial biosynthetic approaches to new erythromycin analogs such a prospect is particularly exciting as there exists a clear and very pronounced difference in the reactivities of the C-6 and C-8 centers in 6 and related 14-membered macrolides.

Erythromycin A is readily inactivated via acid catalyzed conversion to its enol ether and 10,11-anhydrospiroketal forms.14 Semisynthetic approaches to circumvent this problem have been described but remain challenging due to the complexity of the erythromycin scaffold.19 A shunt metabolite of $\mathbf{4 , 1}$ represents a novel aglycone for chemical and/or enzymatic glycosylation approaches to new erythromycin congeners with enhanced stability and/or altered modes of action. Moreover, the C-14 hydroxyl and C-6 epoxide both represent new opportunities for macrolide modifications and new analog design. But discovery of $\mathbf{1}$ and $\mathbf{2}$ provides far more than just new erythromycins for direct analog production. Tremendous insight has been gained regarding erythromycin biosynthesis. Specifically illuminated are issues surrounding TE product diversity, EryF and EryK function and substrate flexibility, potentially exploitable oxygenases lying beyond the cluster (responsible for $\mathrm{C}-14$ oxidation in 1), and the possible origins of the unusual C-6 epoxide of $\mathbf{1}$.

Finally, the newly discovered Actinopolyspora strain YIM90600 is unique in that it produces large quantities $(300 \mathrm{mg} / \mathrm{L})$ of $\mathbf{4}$, even under sub-optimal growth conditions. The high titer of $\mathbf{4}$ suggests that YIM90600 may prove to be a far superior erythromycin producer following further medium optimization and engineering efforts and thus, may meet erythromycin production/engineering needs not currently met by more well established producers.

\section{Acknowledgments}

We thank the Analytical Instrumentation Center of the School of Pharmacy, UW-Madison, for support in obtaining MS and NMR data. 


\section{References}

(1). Katz L, Ashley G. Chem. Rev. 2005; 105:499-528. [PubMed: 15700954]

(2). (a) Itoh Z, Nakaya K, Suzuki H, Aria H, Wakabayashi K. Am. J. Physiol. 1984; 247:G688-G694. [PubMed: 6507625] (b) Omura S, Tsuzuki K, Sunazuka T, Marui S, Toyoda H, Inatomi N, Itoh Z. J. Med. Chem. 1987; 30:1943-1948. [PubMed: 3669002]

(3). Morimoto S, Takahashi Y, Watanabe Y, Omura S. J. Antibiotics. 1984; 37:343-345.

(4). Bright G, et al. J. Antibiot. 1988; 41:1029-1047. [PubMed: 3139603]

(5). Gasc JC, Gouin d'Ambrieres S, Lutz A, Chantot JF. J. Antibiot. 1991; 44:313-330. [PubMed: 1827435]

(6). (a) Or YS, Clark RF, Wang S, Chu DT, Nilius AM, Flamm RK, Mitten M, Ewing P, Alder J, Ma Z. J. Med. Chem. 2000; 43:1045-1049. [PubMed: 10737737] (b) Hammerschlag MR, Sharma R. Expert Opin. Invest. Drugs. 2008; 17:387-400.

(7). (a) Wang G, Niu D, Qiu Y-L, Phan LT, Chen Z, Polemeropoulos A, Or YS. Org. Lett. 2004; 6:4455-4458. [PubMed: 15548049] (b) Stucki A, Gerber P, Acosta F, Cottagnoud M, Cottagnoud P, Jiang L, Nguyen P, Wachtel D, Wang G, Phan LT. J. Antimicrob. Chemother. 2008; 61:665-669. [PubMed: 18222952]

(8). Nashed, N.; Antille, C.; Bojar, R.; Hardenberg, J.; Kellenberger, L.; Roos, B.; Saurat, J.; Schrenzel, J.; Shapiro, S.; Tran, C. Poster F1-1680 presented at 47th ICCAC Meeting; Chicago. September 2007; (b) Heller S, Kellenberger L, Shapiro S. Antimicrob. Agents Chemother. 2007; 51:1956-1961. [PubMed: 17387155]

(9). Komuro I, Sunazuka T, Akagawa KS, Yokota Y, Iwamoto A, Omura S. Proc. Natl. Acad. Sci. USA. 2008; 105:12509-12514. [PubMed: 18719105]

(10). (a) Gochnauer MB, Leppard GG, Komaratat P, Kates M, Novitsky T, Kushner DJ. Can. J. Microbiol. 1975; 21:1500-1511. [PubMed: 1201505] (b) Yoshida M, Matsubara K, Kudo T, Horikoshi K. Int. J. Syst. Bacteriol. 1991; 41:15-20.(c) Ruan J, Mahmoud A, Zhou Z, Liang H. Int. J. Syst. Bacteriol. 1994; 44:759-763.

(11). (a) Adachi TS, Morimoto S, Kondoh H, Tagate T, Watanabe Y, Sota K. J. Antibiot. 1988; 41:966-975. [PubMed: 2971033] (b) Sasaki J, Mizoue K, Morimototo S, Adachi T, Omura S. J. Antibiot. 1988; 41:908-915. [PubMed: 2971032]

(12). (a) Staunton J, Wilkinson B. Chem. Rev. 1997; 97:2611-2629. [PubMed: 11851474] (b) Katz L. Chem. Rev. 1997; 97:2557-2575. [PubMed: 11851471]

(13). Lambalot RH, Cane DE, Aparacio JJ, Katz L. Biochemistry. 1995; 34:1858-1866. [PubMed: 7849045]

(14). Hassanzadeh A, Barber J, Morris GA, Gorry PA. J. Phys. Chem. A. 2007; 111:10098-10104. [PubMed: 17880049]

(15). (a) Cortes J, Wiesmann KEH, Roberts GA, Brown MJB, Staunton J, Leadlay PF. Science. 1995; 268:1487-1489. [PubMed: 7770773] (b) Kao CM, Luo G, Katz L, Cane DE, Khosla C. J. Am. Chem. Soc. 1995; 117:9105-9106.(c) Kao CM, Luo G, Katz L, Cane DE, Khosla C. J. Am. Chem. Soc. 1996; 118:9184-9185.

(16). Cryle MJ, Stok JE, DeVoss JJ. Aust. J. Chem. 2003; 56:749-762.

(17). Hashimoto T, Matsuda J, Yamada Y. FEBS Lett. 1993; 329:35-39. [PubMed: 8354403]

(18). Gaisser S, Lill R, Staunton J, Mendez C, Salas J, Leadlay PF. Mol. Microbiol. 2002; 44:771-781. [PubMed: 11994157]

(19). (a) Asensio, R.; Cruzado, MC.; Diaz, LA.; Ribe, N.; Sempere, J.; Borrell, JI. U. S. Patent Appl. Publ CODEN: USXXCO US 2003023053. 2003. p. 4(b) Brunet E, Muñoz MD, Parra F, Mantecón S, Juanes O, Rodríguez-Ubis JC, Cruzado M-C, Asensió R. Tetrahedron Lett. 2007; 48:1321-1324. 


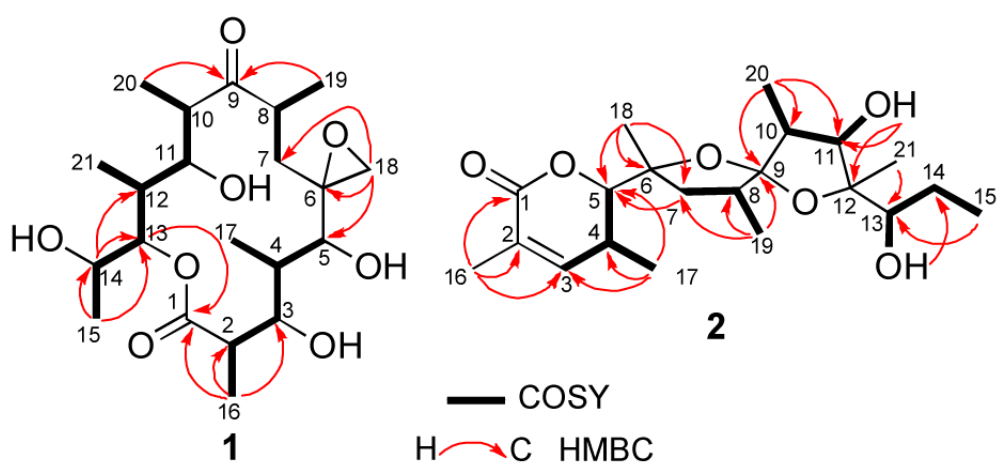

Figure 1.

Key COSY and HMBC correlations for $\mathbf{1}$ and $\mathbf{2}$. 


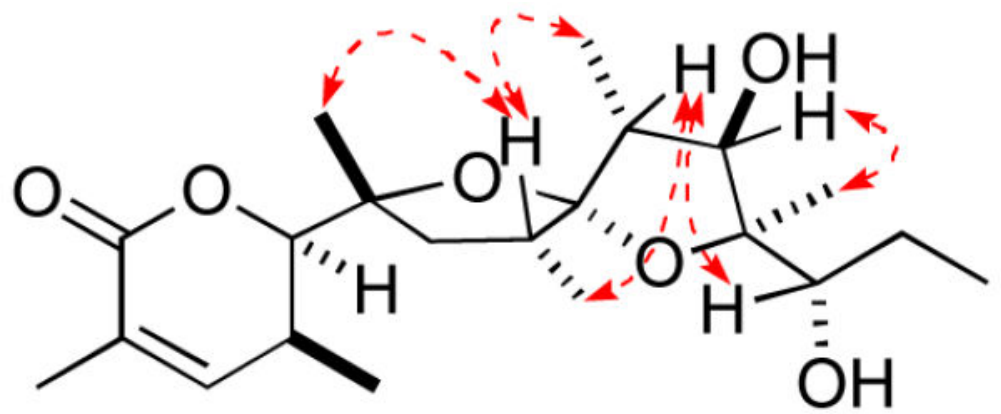

$$
\mathrm{H} \leftrightarrow \mathrm{H} \text { ROESY }
$$

Figure 2.

Key ROESY correlations for 2. 

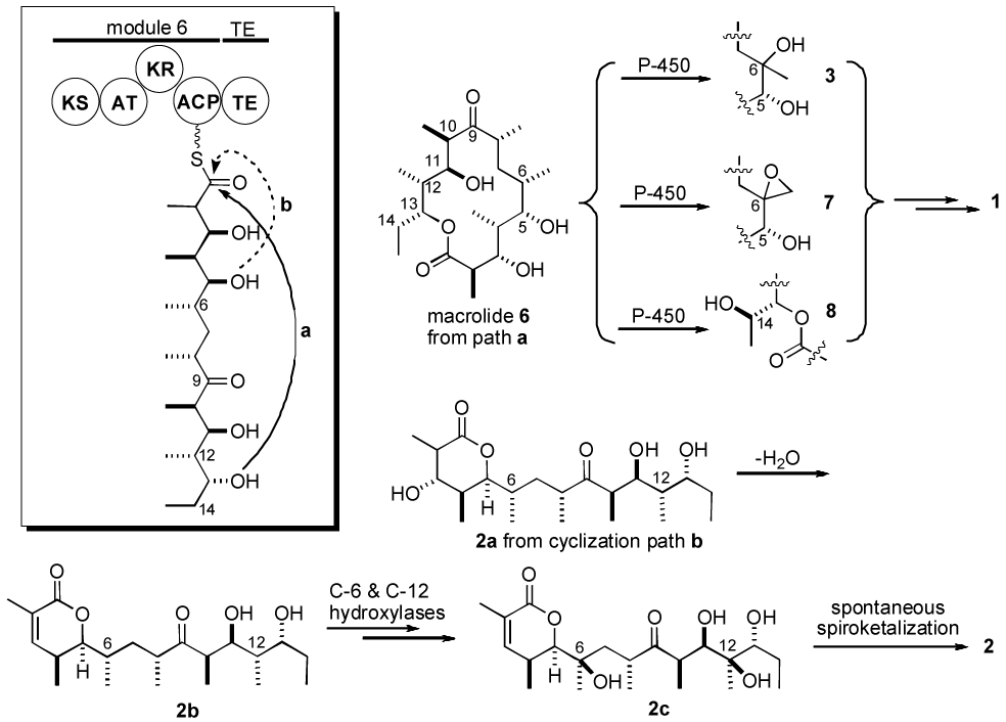

Scheme 1.

Proposed biosynthesis of $\mathbf{1}$ and 2. Polyketide release via cyclization paths a and $\mathbf{b}$ (boxed) afford macrolide $\mathbf{6}$ and lactone $\mathbf{2 a}$; both serve as substrates of multiple oxygenases en route to $\mathbf{1}$ and 2. Molecular fragments not shown for 3, 7, and $\mathbf{8}$ are identical to those of their precursor 6. KS, ketosynthase; AT, acyl transferase; KR, ketoreductase; ACP, acyl carrier protein; TE, thioesterase. 
Table 1

${ }^{1} \mathrm{H}$ and ${ }^{13} \mathrm{C}$ NMR Data of Compounds $\mathbf{1}$ and $\mathbf{2}^{a}$

\begin{tabular}{|l|l|l|l|l|}
\hline \multirow{2}{*}{ No. } & \multicolumn{2}{|c|}{$\mathbf{1}^{b}$} & \multicolumn{2}{c|}{$\mathbf{2}^{\boldsymbol{c}}$} \\
\cline { 2 - 5 } & ${ }^{1} \mathbf{H}($ mult., $\boldsymbol{J}$ in Hz) & ${ }^{13} \mathbf{C}$ & ${ }^{1} \mathbf{H}($ mult, $\boldsymbol{J}$ in Hz) & ${ }^{13} \mathbf{C}$ \\
\hline 1 & & $175.8(\mathrm{~s})$ & & $166.7(\mathrm{~s})$ \\
\hline $2 \mathrm{a}$ & $2.60(\mathrm{~m})$ & $44.2(\mathrm{~d})$ & & $126.8(\mathrm{~s})$ \\
\hline 3 & $3.73(\mathrm{~d}, 10.8)$ & $77.7(\mathrm{~d})$ & $6.63(\mathrm{dd}, 6.5,1.5)$ & $146.4(\mathrm{~d})$ \\
\hline 4 & $1.88(\mathrm{~m})$ & $37.7(\mathrm{~d})$ & $2.56(\mathrm{~m})$ & $31.1(\mathrm{~d})$ \\
\hline 5 & $4.00(\mathrm{br} \mathrm{s})$ & $71.6(\mathrm{~d})$ & $4.34(\mathrm{~d}, 3.0)$ & $84.8(\mathrm{~d})$ \\
\hline 6 & & $58.8(\mathrm{~s})$ & & $82.3(\mathrm{~s})$ \\
\hline $7 \mathrm{a}$ & $2.38(\mathrm{br} \mathrm{d}, 13.8)$ & $37.3(\mathrm{t})$ & $1.94(\mathrm{t}, 12.0)$ & $40.0(\mathrm{t})$ \\
\hline $7 \mathrm{~b}$ & $0.83(\mathrm{br} \mathrm{d}, 13.8)$ & & $1.75(\mathrm{br} \mathrm{d}, 12.0)$ & \\
\hline 8 & $2.91(\mathrm{~m})$ & $38.5(\mathrm{~d})$ & $2.16(\mathrm{~m})$ & $36.8(\mathrm{~d})$ \\
\hline 9 & & $212.9(\mathrm{~s})$ & & $113.8(\mathrm{~s})$ \\
\hline 10 & $2.71(\mathrm{~m})$ & $44.5(\mathrm{~d})$ & $2.03(\mathrm{~m})$ & $45.4(\mathrm{~d})$ \\
\hline 11 & $3.64(\mathrm{~m})$ & $71.5(\mathrm{~d})$ & $3.93(\mathrm{dd}, 9.6,5.5)$ & $86.4(\mathrm{~d})$ \\
\hline 12 & $1.58(\mathrm{~m})$ & $38.7(\mathrm{~d})$ & & $82.1(\mathrm{~s})$ \\
\hline 13 & $5.12(\mathrm{~d}, 9.1)$ & $78.2(\mathrm{~d})$ & $3.56(\mathrm{br} \mathrm{d}, 10.5)$ & $77.3(\mathrm{~d})$ \\
\hline $14 \mathrm{a}$ & $3.71(\mathrm{~m})$ & $67.0(\mathrm{~d})$ & $1.72(\mathrm{~m})$ & $23.6(\mathrm{t})$ \\
\hline $14 \mathrm{~b}$ & & & $1.45(\mathrm{~m})$ & \\
\hline 15 & $1.00(\mathrm{~d}, 6.8)$ & $20.7(\mathrm{q})$ & $1.00(\mathrm{t}, 6.4)$ & $11.5(\mathrm{q})$ \\
\hline 16 & $1.11(\mathrm{~d}, 6.8)$ & $15.3(\mathrm{q})$ & $1.90(\mathrm{br} \mathrm{s})$ & $17.2(\mathrm{q})$ \\
\hline 17 & $0.89(\mathrm{~d}, 6.8)$ & $5.9(\mathrm{q})$ & $1.07(\mathrm{~d}, 7.0)$ & $13.7(\mathrm{q})$ \\
\hline $18 \mathrm{a}$ & $2.76(\mathrm{~d}, 7.0)$ & $46.9(\mathrm{t})$ & $1.25(\mathrm{~s})$ & $24.0(\mathrm{q})$ \\
\hline $18 \mathrm{~b}$ & $2.27(\mathrm{~d}, 7.0)$ & & & $21.9(\mathrm{q})$ \\
\hline 19 & $0.95(\mathrm{~d}, 6.2)$ & $14.5(\mathrm{q})$ & $0.98(\mathrm{~d}, 6.4)$ & $13.0(\mathrm{q})$ \\
\hline 20 & $0.77(\mathrm{~d}, 6.4)$ & $6.7(\mathrm{q})$ & $1.03(\mathrm{~d}, 7.0)$ & $11.5(\mathrm{q})$ \\
\hline 21 & $0.79(\mathrm{~d}, 6.4)$ & $10.5(\mathrm{q})$ & $1.27(\mathrm{~s})$ & \\
\hline
\end{tabular}

${ }^{a}$ Signals were assigned with aid of ${ }^{1} \mathrm{H}_{-}{ }^{1} \mathrm{H}$ COSY, HMQC, and HMBC experiments

${ }^{b}$ Data were recorded in DMSO- $d 6$

${ }^{c}$ Data were recorded in $\mathrm{CDCl}_{3}$. 